\title{
UMA VOZ A ECOAR: A LEITURA SOBRE A CIDADE
}

\author{
Isabella Araujo \\ Doutoranda em Geografia, UERJ. \\ isaaraujo@hotmail.com
}

\section{Resumo:}

Este artigo traz ao diálogo a relação entre a formação de professores e a leitura sobre a cidade. O texto apresenta a minha própria formação e experiência docente e a relação com o Curso de Extensão (A) "gente do patrimônio": oficinas de alfabetização patrimonial e formação de professores de São Gonçalo, proporcionado pelo Grupo de Pesquisa Vozes da Educação, da Faculdade de Formação de Professores da Universidade do Estado do Rio de Janeiro (UERJFFP), ocorrido no ano de 2006. Além disso, abordamos sobre as possibilidades de ler o local, a cidade e construir outras possibilidades pedagógicas que visem à educação para a cidade, o exercício da cidadania e a escola como um ambiente privilegiado de circularidade de saberes.

Palavras-chave: Formação de Professores; Educação Patrimonial; Memória, Leitura da Cidade.

\begin{abstract}
:
This article aims to comment about the relationship between the teacher's career and the reading of the city. The text presents my own career and teaching experience with the mini-specialization training on Patrimony Agent: literacy patrimony workshops and São Gonçalo teachers training, provided by the Research Group Vozes da Educação, from Faculdade de Formação de Professores da Universidade do Estado do Rio de Janeiro (UERJ-FFP), occurred in the year 2006. Additionally, we approach about the possibilities of reading the place, the city and build another pedagogical possibilities aiming to the city education, the citizenship and the school as a privileged environment of knowledge sharing.
\end{abstract}

Key-words: Teacher's career; Heritage Education; Memory; Reading of the City.

\section{UMA VOZ A ECOAR: A LEITURA SOBRE A CIDADE}

\section{Palavras iniciais}

Ninguém começa a ser educador numa certa terçafeira às quatro horas da tarde. Ninguém nasce educador ou marcado para ser educador. A gente se faz educador, a gente se forma como educador, 
permanentemente, na prática e na reflexão sobre a prática

Paulo Freire (1991, p.32)

O título do artigo está marcado pelo verbo intransitivo ecoar, isto é, produzir eco, reverberar, repercutir, ressoar. Para além da mera repetição de uma voz, ecoar também pode ser se fazer ouvir em longa distância e é nesse sentido que começo o meu texto, querendo-me fazer ouvir, disseminar a minha voz ao contar e socializar a minha experiência como professora em constante formação e transformação. Além disso, o ato de narrar, de escrever é, de certo modo, uma maneira de encontro conosco e com o mundo que nos cerca. Sendo assim, "as narrativas revelam o modo como os seres humanos experienciam o mundo" (ALARCÃO, 2010, p. 57).

Além de elucidar o título, não poderia deixar de fazer referência ao educador Paulo Freire que nos presenteia com essas palavras da epígrafe. Esse pequeno trecho nos apresenta algumas concepções de suma relevância para a sustentação do que é ser educador: é um processo e, além disso, a educação na perspectiva democrática acontece através do movimento prática-reflexãoprática.

Desta forma, iniciarei o texto contanto um pouquinho da minha história de formação e, assim, refletirei sobre minhas práticas e experiências docentes. Como afirmam Perez, Araújo e Tavares (2006): “As histórias nos ensinam, mantêm-se vivas na memória dos que as ouvem quando são assimiladas às suas experiências pessoais" (PEREZ, ARAÚJO \& TAVARES, 2006, p. 42).

Nessa mesma perspectiva, Boaventura de Sousa Santos (2010) em seu livro Um discurso sobre as ciências, ao abordar as concepções do paradigma emergente, define, entre outras questões, que todo conhecimento é autoconhecimento e, consequentemente, a ciência é autobiográfica. Desta forma, "a ciência não descobre, cria, e o acto criativo protagonizado por cada cientista e pela comunidade científica no seu conjunto tem de se conhecer intimamente antes que conheça o que com ele se conhece do real” (SANTOS, 2010, p. 83). Então, é a partir deste movimento narrativo que tentarei me autoconhecer e, assim, produzir conhecimento.

Sou pedagoga e historiadora. Formei-me pela Universidade Federal Fluminense e pela Universidade do Estado do Rio de Janeiro, na Faculdade de Formação de Professores, Campus São Gonçalo-RJ. O magistério entrou em minha vida como uma grata surpresa, pois na infância e adolescência não havia pensado em me tornar professora. No entanto, ao ingressar no cursinho pré-vestibular, eu conheci pessoas e leituras que me auxiliaram a descortinar os olhos e enxergar um mundo desigual e, consequentemente, injusto. Posso dizer que me revolucionei. Já não era a mesma, assim como tudo ao meu redor também se mostrava diferente. 
Nessa época eu era uma garota de 15 para os 16 anos, cheia de planos, sonhos e vida. A pressão familiar era grande para que eu me direcionasse para os cursos de Administração, Ciências Contábeis, Economia e áreas afins. Inclusive, no meu primeiro vestibular, tentei para Administração, mas confesso que me auto sabotei e realizei péssimas provas na segunda etapa do vestibular, justamente para não passar. Nessa mesma época havia a promessa de emprego garantido assim que completasse 18 anos, caso estivesse em qualquer curso que contemplasse a área empresarial, uma vez que nesse período eu era menor estagiária em uma grande empresa multinacional. No entanto, algo crescia em mim: era o desejo de lutar por um mundo menos desigual e injusto. Diante do exposto, renunciei a todas essas influências para seguir outros caminhos: o meu caminho, que não se daria de forma solitária nem tinha como propósito apenas o meu enriquecimento pessoal.

Ingressei nas duas universidades quase o mesmo tempo. Foram anos de muitos aprendizados, experiências e conhecimentos de outras realidades. Também foram anos duros, pois a minha família passava por dificuldades financeiras e, além disso, nos primeiros períodos tive dificuldade de arranjar bolsas ou estágios que pudessem me proporcionar certa flexibilidade para seguir nos dois cursos. Resisti às diversas barreiras e com muita disciplina eu consegui me formar dentro do tempo previsto dos cursos, mesmo realizando estágios e tentando aprender na prática o que me era ensinado em sala de aula.

Durante as graduações tive uma vida universitária intensa e tentei experienciar por meio de estágios e bolsas a profissão que havia escolhido para mim. Uma das minhas experiências mais significativas foi ter participado do Grupo de Pesquisa Vozes da Educação como bolsista de iniciação científica do Conselho Nacional de Pesquisa (CNPq), no subprojeto Alfabetização, Memória e Formação de Professores, sob orientação da Professora Doutora Mairce da Silva Araujo, entre os anos 2006 e 2008.

Ser integrante do Grupo de Pesquisa Vozes da Educação me proporcionou conhecer o mundo da pesquisa universitária e, sobretudo, assumir a autoria de minha formação acadêmica. Comecei a compreender melhor o papel docente, a alfabetização para além da decodificação das palavras, a realizar uma leitura do passado com os olhos do presente, entre tantas outras aprendizagens e influências que hoje ajudam a compor a profissional que sou.

Ao ingressar no Grupo de Pesquisa Vozes da Educação, eu era uma moça de 21 anos, cheia de sonhos e projetos. O Grupo Vozes da Educação na ocasião comemorava os seus 10 anos (confesso que gosto de marcos comemorativos). Logo, estou nessa estrada junto ao Grupo de Pesquisa Vozes da Educação há exatos 10 anos de muitas memórias, aprendizados e 
experiências. Como historiadora não poderia deixar de mencionar os marcos cronológicos que temos necessidade de demarcar. Segundo o historiador Jacques Le Goff (1990):

\begin{abstract}
Matéria fundamental da história é o tempo; portanto, não é de hoje que a cronologia desempenha um papel essencial como fio condutor e ciência auxiliar da história. $\mathrm{O}$ instrumento principal da cronologia é o calendário, que vai muito além do âmbito do histórico, sendo mais que nada o quadro temporal do funcionamento da sociedade. $\mathrm{O}$ calendário revela o esforço realizado pelas sociedades humanas para domesticar o tempo natural (LE GOFF, 1990, p. 8).
\end{abstract}

Os dois anos em que estive junto ao Grupo Vozes da Educação na qualidade de bolsista foram anos de muitos aprendizados, pois participei de leituras, rodas de conversas, grupos de estudos, eventos nacionais e internacionais (foi a primeira vez que tive a oportunidade de viajar de avião para um Congresso Internacional sobre História da Educação, em Aracati-CE). Além disso, possibilitou-me um mundo que eu não conhecia ou ainda não tinha consciência de como funcionava: o universo da pesquisa acadêmica, mas com um diferencial, pois sempre esteve unida ao ensino e à extensão, logo nos proporcionando um ambiente para nos tornarmos professores-pesquisadores plenos.

Além disso, o "Vozes", como é mais conhecido entre os íntimos, proporcionou-me uma maneira mais humana de ver e sentir o mundo, sempre me pondo no lugar do outro. Foi o que a educadora Nilda Alves (2001) propôs em seu artigo intitulado Decifrando o pergaminho - o cotidiano das escolas nas lógicas das redes cotidianas, presente no livro Pesquisa no/do cotidiano das escolas: sobre redes de saberes, cuja organização é da própria Professora Nilda Alves e da Professora Inês Barbosa de Oliveira. Ao escrever sobre o sentimento do mundo, Alves enfatiza que para se produzir pesquisa no cotidiano, exige-se "do pesquisador que se ponha a sentir o mundo e não só a olhá-lo, soberbamente, do alto ou de longe (...) é exigida uma outra postura epistemológica" (ALVES, 2001, p. 16). E foi assim me iniciei como professorapesquisadora.

\title{
Leitura sobre a cidade
}

Foi também no Grupo Vozes da Educação que tive o primeiro contato com o conceito de Educação Patrimonial. Estávamos no ano de 2006 e, na qualidade de bolsista, participei do Curso de Extensão (A) "gente do patrimônio": oficinas de alfabetização patrimonial e formação de professores de São Gonçalo, sob a coordenação das Professoras Doutoras Carmen Lúcia Vidal Perez, Mairce da Silva Araújo e Maria Tereza Goudard Tavares e, consequentemente, 
fruto da parceria entre o Grupo de Pesquisa Vozes da Educação e Grupo de Estudos e Pesquisas Escola, Memória e Cotidiano - GEPEMC-UFF.

Essa foi a minha primeira experiência concreta de ensino-pesquisa-extensão e a minha primeira leitura acadêmica sobre a cidade de São Gonçalo, na qual sou nascida e criada. Ao longo do curso, as professoras foram trabalhando conosco sobre os patrimônios gonçalenses, sobretudo pedindo para que pesquisássemos em nossos bairros e, então, percebi como eu e tantos outros colegas desconhecíamos o município onde morávamos, estudávamos ou trabalhávamos e isso muito me incomodou.

Antes do curso, eu tinha a sensação de que quando viajava aprendia muitas coisas sobre os lugares para onde ia. Sempre me encantou conhecer a cultura, os monumentos, as tradições, as belezas naturais dos espaços que conhecia. Entretanto, não tinha o mesmo sentimento com a minha cidade de origem. Apesar de olhar certas construções, marcas deixadas pelo passado, que até me despertavam a curiosidade, pela correria cotidiana ficavam sempre para depois, para quando desse tempo.

Desta forma, o referido curso despertou em mim um desejo muito grande de conhecer melhor a cidade que eu habito e habita em mim. Nos encontros presenciais nós, bolsistas, profissionais da educação da rede municipal e estudantes universitários, pesquisávamos, discutíamos e produzíamos materiais didático-pedagógicos e, assim, aprimorávamos a nossa identidade, o nosso sentimento de pertencimento enquanto munícipes e/ou trabalhadores/estudantes da cidade.

Cabe ressaltar que era a educação reflexiva/crítica que norteava o nosso trabalho no curso e que acabou me amparando como educadora em constante formação. Comecei a compreender o movimento de prática-reflexão-prática que tanto ouvia em sala de aula, mas que foi necessário vivenciar no curso para compreender, de fato, esse movimento de pesquisa.

Neste sentido, mais uma vez eu recorro às palavras de Boaventura de Sousa Santos, no que tange às trajetórias de vida pessoais e coletivas na construção do conhecimento:

(...) Hoje sabemos ou suspeitamos que as nossas trajectórias de vida pessoais e colectivas (enquanto comunidades científicas) e os valores, as crenças e os prejuízos que transportam são a prova íntima do nosso conhecimento, sem o qual as nossas investigações laboratoriais ou de arquivo, os nossos cálculos ou os nossos trabalhos de campo constituiriam um emaranhado de diligências absurdas sem fio nem pavio (SANTOS, 2010, p. 85).

Além disso, o curso supracitado foi amparado na perspectiva freireana, isto é, nas concepções do educador Paulo Freire, o qual defendeu e difundiu que "aprender a ler e escrever 
é antes de mais nada aprender a ler o mundo, compreender o contexto, localizar-se no espaço social mais amplo" (PEREZ, ARAÚJO e TAVARES, 2006, p. 6). E é também nessa perspectiva que eu tenho me construído como professora.

Para fins de melhor elucidação, o curso foi dividido em sete oficinas, a saber: nomes e lugares; lugares da memória; caminhos do patrimônio; contadores e catadores de histórias; um baú de memórias: relações intergeracionais na escola; imagens do patrimônio: a cidade que se revela/oculta nas lentes fotográficas; a aula-passeio: a cidade como um livro de espaço. Tais oficinais tinham como objetivos: ampliar os conhecimentos sobre a história e a memória local; desenvolver os conceitos de patrimônio, memória, história, história local, história oral, cultura, identidade, educação e alfabetização patrimonial; produzir materiais didáticos sobre a história e memória local; conhecer os patrimônios gonçalenses e refletir sobre o tratamento dado a esses patrimônios, dentre outros.

A temática do curso e um dos seus principais conceitos, a Educação Patrimonial, motivaram-me a escrever o meu trabalho monográfico de graduação. Assim, as minhas andanças pela cidade se configuraram na minha principal pesquisa de campo, que me permitia ler, estudar, observar as placas das ruas, as praças, os colégios, as estátuas, os prédios, as casas, etc. que me faziam pensar sobre quem deveriam ser aquelas pessoas que tinham os seus nomes evidenciados nesses locais e o porquê desses nomes e não de tantos outros.

Assim, por meio das imagens e escritos da cidade, foi o modo que encontrei para agir e representar o lugar, o cotidiano, as maneiras de viver dos munícipes. Como diz Pesavento (1997):

A cidade é em si uma realidade objetiva com suas ruas, construções, monumentos, praças, mas sobre esse 'real' os homens constroem um sistema de ideias e imagens de representação coletiva. Ou seja, através de discursos e imagens, o homem re-apresenta a ordem social vivida, atual e passada, transcendendo a realidade insatisfatória (PESAVENTOS, 1997, p. 26).

Na cidade de São Gonçalo nós temos algumas vias, praças, colégios, que levam nomes de pessoas, como: Ari Parreiras, Feliciano Sodré, Dr. March, Paul Leroux, Nilo Peçanha, Alfredo Backer, Dr. Francisco Portela, Pio Borges, Coronel Cerrado, Vicente Lima Cleto, Yolanda Saad Abusaid, Estephânia de Carvalho. Há outros nomes que têm outras origens, como fatos históricos, nomes de outros lugares, nomes de santos e, ainda, homenageados por outras motivações como, por exemplo, os nomes: Avenida 18 do Forte, Av. São Miguel, Av. São Paulo, Av. Maricá, Rua da Feira, Praça Zé Garoto, etc. 
Por meio de pesquisas documentais e obras de autores que abordam a história gonçalense pude satisfazer algumas dessas curiosidades e, a partir de então, pude perceber que a minha relação com a cidade passou a ser como a de quem retira uma venda dos olhos e consegue lê-la.

De forma mais ou menos consciente à época, hoje tenho a clareza de que esse foi o pontapé para a minha entrada no Mestrado em Geografia: Produção Social do Espaço Natureza, Política e Processos Formativos em Geografia, na UERJ-FFP, também no campus São Gonçalo, sendo orientada pelo Professor Doutor Ruy Moreira. Tinha necessidade de conhecer sobre o lugar, sobre a cidade e sobre mim. E foi assim que a Geografia entrou em meu currículo e na minha vida. Foram dois anos de muitas novidades, aprendizados, apropriação de novos conceitos e de confluência com aprendizados anteriores.

Hoje, mais instrumentalizada com os conceitos geográficos, ouso fazer a seguinte pergunta: mas o que é cidade? Para responder a essa pergunta, que ao mesmo tempo parece tão simples e tão complexa, recorremos a Cavalcanti (2008), que expõe as diversas possibilidades de reflexão. Inicialmente, podemos definir a cidade como uma aglomeração de pessoas e de objetos, edificações (CAVALCANTI, 2008, p. 87). No entanto, a cidade e o seu conceito é de definição complexa e vai para além de uma definição simplista. Além disso, sabemos que é o lugar de produção social, no qual se constitui a identidade. A cidade pode ser definida como um arranjo espacial (paisagem); como um modo de vida, isto é, como resultado e condição para a prática social e, por fim, a cidade como modo de produção, mais precisamente como um arranjo espacial histórico que produz/reproduz determinadas formas de organização e de produção social. Assim, a cidade é conceituada e estudada para além das formas físicas, mas também por meio dos modos de vida, dos espaços simbólicos (CAVALCANTI, 2008, p. 58).

Falar em cidade também é falar em lugar. Na perspectiva de Cavalcanti (2008), é no lugar que acontece a vida cotidiana, familiar, afetiva, identitária, mas também é onde se concretizam as relações globais. Nas palavras da autora:

(...) a cidade é um lugar bastante complexo, de produção social, no qual a identidade é vivida em fronteiras difusas, permeáveis, com muitos espaços de contato, de resistências e de exclusão, em que há manifestação de diferentes percepções, usos, culturas e aspirações de distintos grupos, em seus espaços públicos e privados. Esse fato leva a pensar a cidade como um território, ou como um espaço que expressa uma infinidade deles (CAVALCANTI, 2008, p. 56).

Desta forma, a cidade também pode ser definida como um espaço geográfico, como um lugar de existência cotidiana produzida pelos sujeitos. Sendo assim, a cidade é espaço das 
diversas culturas e da coexistência, no qual interagem valores, sentidos e símbolos diversos, plurais. No entanto, essa coexistência raramente se dá sem disputas, sem conflitos, de forma harmônica. Nas palavras de Cavalcanti: "a cidade é o lugar da diferença, do contato, do conflito, o que pressupõe menor divisão/superação espacial, menor dispersão, maior convívio entre os diferentes, menor desigualdade social” (CAVALCANTI, 2008, p. 116 e 117).

Como neste artigo falamos em cidade urbana, é nessa perspectiva de inacabamento, de espaço em constante transformação, que recorremos a Lefebvre (2002) para definir a sociedade urbana:

O urbano (abreviação de "sociedade urbana") define-se (...) não como realidade acabada, situada, em relação à realidade atual, de maneira recuada no tempo, mas, ao contrário, como horizonte, como virtualidade iluminadora. O urbano é o possível, definido por uma direção, no fim do percurso que vai em direção a ele. Para atingi-lo, isto é, para realizá-lo, é preciso em princípio contornar ou romper os obstáculos que atualmente o tornam impossível. (LEFEBVRE, 2002, p. 28).

Cavalcanti, amparada em Santos e Lefebvre, distingue os conceitos de espaço urbano e cidade, pois não representam a mesma coisa. Sendo assim, "a cidade é a forma, é a materialização de determinadas relações sociais, enquanto espaço urbano é o conteúdo, são as próprias relações sociais que se materializam no espaço" (CAVALCANTI, 2008, p. 66). No entanto, a autora também alerta que não é possível fazer uma separação abrupta desses conceitos, pois há uma relação de interdependência entre a forma e o conteúdo, leia-se: entre cidade e espaço urbano.

E como podemos ler a cidade? A urbe pode ser lida sob várias perspectivas e ciências: pela Arquitetura, História, Engenharia, Geografia, Sociologia, entre outras. E as análises podem estar centradas em questões como o cotidiano, políticas públicas, planejamento urbano, gestão da cidade, etc. A leitura que fiz sobre a cidade, ainda na própria graduação em História, estava amparada mais em lê-la pela perspectiva das marcas de memórias, isto é, pelos vestígios do passado. Li de forma crítica os lugares de memória, isto é, os patrimônios do município de São Gonçalo, nos quais se cruzam memórias individuais e coletivas, lembranças e esquecimentos/silenciamentos, relações de poder, usos (e abusos) pelos diversos grupos e/ou sujeitos e, assim, a leitura da cidade também ajudou a me constituir como professora.

Nas palavras de Pérez, Tavares e Araújo (2009):

A complexidade do mundo contemporâneo coloca para a escola e a formação de professor@s o desafio de incorporar as diferentes leituras de mundo e os

Revista Interinstitucional Artes de Educar. Rio de Janeiro, V. 2 N. Especial - pag 266-279 (jun - out 2016): "Vozes da Educação" 
diversos contextos culturais à pluralidade de significações e à multiplicidade de saberes, que constituem a alteridade dos vários atores que circulam no cotidiano da escola. Essa alteridade se expressa nas diferentes leituras do espaço urbano (PÉREZ, TAVARES E ARAUJO, 2009, P. 31).

Deste modo, a cidade nos revela muitas coisas, muitos lugares de memória: construções, imagens, palavras, contradições, tradições, práticas, saberes, fazeres, celebrações, ritos. Esses lugares podem ser materializados em ruas, museus, arquivos, clubes, igrejas, escolas, universidades, sindicatos, ruínas, etc. no qual se cruzam e entrecruzam muitas histórias e muitas lembranças, quer elas sejam individuais e/ou coletivas. Os lugares de memória também podem ser imateriais, isto é, não contar com uma edificação, um bem de pedra e cal, mas através de saberes, fazeres, ritos e tradições. Como por meio de festas, músicas, comidas e tudo o que sustente a memória de um local e/ou grupo. E todos esses elementos, os bens materiais e imateriais, contribuem para construir a identidade e o sentimento de pertencimento de um grupo.

Cabe ressaltar que há relações de poder no que pode ser lembrado ou no que se quer silenciar e/ou esquecer. Costumeiramente, as práticas populares costumam não possuir muito prestígio ou visibilidade, mas muitas das vezes são apropriadas pelas classes dominantes e são exploradas com finalidades comerciais, turísticas. É o caso do samba, no Rio de Janeiro; das práticas religiosas do Candomblé, na Bahia; dentre tantos exemplos que podíamos citar. Nesse jogo do que se quer promover como lembrança ou levar ao esquecimento/ silenciamento, há sérias implicações na proteção e conservação desses bens, logo correndo o risco de esquecermos parte de nossa história, de nossa memória. Deste modo, a cidade tem uma história contada a cada esquina e nós fazemos parte dessa história, pois estamos inseridos em um tempo e num espaço e, por isso, mudamos, transformamos o mundo a partir de nossa existência.

Barros (2004), em seu livro Breves notas ao ensino de História da Educação, discute sobre a cidade como discurso, memória e história e, para isso, dialoga com a questão do olhar. Discute que ao estudarmos uma cidade, observando seus detalhes, estamos praticando outra forma de olhar, diferente do olhar corriqueiro que quase nada observa as pessoas e os lugares. "Visitar uma cidade possibilita pensá-la como "educadora" de nossas percepções". (BARROS, 2004, p. 116).

Barros também nos fala de uma educação do olhar, isto é, realizar uma leitura para além do que está posto inicialmente perante os nossos olhos e, assim, conseguir desenvolver análise sob vários ângulos - social, cultural, político, econômico, etc. É saber ler nas entrelinhas. Cabe salientar que as cidades acumulam saberes e que muitas vezes os utilizamos e nem nos damos conta, pois a cidade nos habita e nós habitamos a cidade e, deste modo, 
produzimos/reproduzimos uma linguagem própria da localidade, costumes, maneiras de pensar e agir. Então concluímos que a cidade é um local privilegiado de criação e socialização de saberes. Dentro dessa perspectiva, as cidades começaram a ser vistas e consideradas como um local de produção social e, consequentemente, de produção cultural, fruto do grande contingente populacional e resultado do crescente processo de industrialização dos países.

Dentro desse prisma, podemos compreender a cidade como um livro, isto é, que pode ser lida (sua paisagem, seus usos, as relações de poder, as produções e usos cotidianos, etc.), que é repleta de significações e possíveis escritas e, dentro de uma perspectiva democrática, pode ser escrita para muito além da ótica dominante. Essa escrita para além da ótica dominante pode ser grafada, lida e compreendida a partir das resistências e dos combates de grupos e indivíduos que lutam pelos seus lugares de memória, pelas suas versões na construção/produção cotidiana que acontecem nas cidades. Arrisco-me ao dizer que esses lugares também se constituem com lugares de reinvindicações, de expressão, de resistências, de manifestações.

Gomes (2012) assim enfatiza:

Os espaços públicos são, nesse sentido, lugares onde os problemas são assinalados e significados, um terreno onde se exprimem tensões, o conflito se transforma em debate, e a problematização da vida social é posta em cena. Ele constitui, por isso, uma arena de debates, mas também um terreno de reconhecimento e de inscrição dos conflitos sociais. Por essa razão, esses espaços são marcadores fundamentais da transformação social (GOMES, 2012, p. 24).

Inspirada nas palavras de Barros (2004) e Cavalcanti (2008) ressalto que a cidade é um lugar propício e potencializador de formação e transformação, ainda mais quando pensamos na promoção da cidadania e na luta pelo direito à cidade e, consequentemente, ao direito à cidadania. É o lugar de promover a formação cidadã para uma vida participativa em sua cidade, em seu lugar de convívio cotidiano, isto é, no seu lugar de moradia, produção e circulação. Cabe enfatizar que habitar é muito mais que morar, isto é, um direito de compreender sua história, de frequentar a cidade, usufruir de direitos e lutar por eles, ter o direito de construir sua própria identidade e cultura (CAVALCANTI, 2008, p. 90), é formar-se cidadão pleno e consciente.

Nessa perspectiva:

A cidade é educadora: ela educa, ela forma valores, comportamentos, ela informa com suas espacialidades, com seus sinais, com suas imagens, com sua escrita. Ela também é um conteúdo a ser apreendido por seus habitantes. No entanto, as possibilidades de leitura mais abrangente da cidade dependem de uma formação do cidadão. A prática da cidadania inclui a competência para se

Revista Interinstitucional Artes de Educar. Rio de Janeiro, V. 2 N. Especial - pag 266-279 (jun - out 2016): "Vozes da Educação" 
fazer a leitura da cidade. Ser cidadão é exercer o direito de morar, de produzir e de circular na cidade; é exercer o direito a criar seu direito à cidade, é cumprir o dever de garantir o direito coletivo à cidade [...] (CAVALCANTI, 2001, p. 23).

Segundo Motta, "as cidades serão sempre construções coletivas dos homens, ou seja, serão sempre produtos culturais" (MOTTA, 2008, p. 45), propiciando as relações humanas, pois os homens começam a construir, organizar, reorganizar o local onde vivem e, com isso, as modificações são notadas com o passar do tempo. O entorno muda, outras gerações surgem e as pessoas que habitam aquele espaço também mudam e, conseqüentemente, as relações sociais e culturais também sofrem suas alterações. Esse processo mostra a dinâmica da cidade em que algumas marcas do passado ficam, mas outras coisas surgem. Essas marcas do passado que permanecem mostram o processo de construção, tornando-se uma forma de registro. Deste modo, as cidades podem ser lidas e interpretadas. Elas também são documentos, fontes históricas, que dizem respeito sobre a cultura, as formas de viver e de fazer de um povo.

Neste sentido, é urgente e necessário pensar sobre a educação para a cidade e para o exercício da cidadania. Apesar de existirem vários outros ambientes possíveis de se promover essa ação educativa, a circularidade de saberes, a escola apresenta-se como um lugar privilegiado da criação e recriação da relação de ensino-aprendizagem e da cultura local. Deste modo, esperase uma escola menos burocrática e/ou funcionalista para a construção de uma escola mais dialógica e relacional entre os sujeitos e seu entorno, com a comunidade e com o local, tornandose um lugar de convivência, isto é, partilhar de uma vida comum; construir contato diário e frequente; desenvolver intimidade, familiaridade. Tais ações podem ocorrer de forma interdisciplinar (desejável) ou, ainda, pelas disciplinas de Geografia, História, Literatura, Ciências e por meio de conceitos como Educação Patrimonial, Lugar, História Local, Memória, etc. cujo objetivo maior é reconhecer, produzir e fazer uso da cidade de forma consciente de sua participação nesse processo e, consequentemente, de seu direito à cidade, como afirmou Lefebvre, em seu livro Direito à cidade (1991). Essa proposta configura-se como um potente modo de construir a pesquisa-ação, isto é, a aprendizagem pela experiência e abordagem reflexiva.

\section{Algumas considerações}

As minhas primeiras experiências na vida acadêmica foram de uma grandeza sem tamanho, mas não sem dor. Isto é, tive que vencer meus medos e deficiências de escrita, vencer a timidez de falar em público ao apresentar trabalhos, sempre me reinventando e tentando dar o 
meu melhor. No entanto, hoje consigo ver que toda essa aprendizagem, mesmo as experiências mais difíceis, serviu de engrandecimento para que hoje eu tenha maior consciência do mundo que me cerca e do universo acadêmico.

Os caminhos percorridos durante a vida universitária foram os mais diversos possíveis. Ora se deu de maneira fácil e ora aconteceu de maneira difícil, já que toda compreensão de conhecimento precisa primeiro nos tocar, para que assim, possamos tocar o outro, motivá-lo, convencê-lo de que é possível.

Estudar sobre o município de meu nascimento durante a graduação e enquanto bolsista foi de grande alegria e valia, pois pude conhecer melhor a minha cidade e, assim, travar uma maior identificação com a localidade que eu habito e que também habita em mim. Também pude descortinar o véu que cobria a minha face e que não me deixava enxergar com clareza as questões políticas, econômicas, sociais, produzidas e reproduzidas ao longo de tantos anos.

Esses caminhos me possibilitaram uma leitura sobre a cidade que habito e que habita em mim, de mim mesma enquanto sujeito de memórias, subjetividade, questionamentos e que permanentemente constitui sua identidade. E é por meio da leitura da cidade que acredito ser possível os sujeitos irem para além do que apenas é visto, isto é, do que está presente nas placas das ruas, avenidas, escolas, praças, fazendo uma leitura do local que os constitui e uma leitura de si mesmos, enquanto sujeitos que produzem conhecimentos e estão em permanente construção de suas identidades e cidadania.

Além disso, percebo que atualmente a minha voz, que já foi amparada pelas vozes de professoras e companheiras de bolsa de pesquisa, faz ecoar em outros ambientes formativos, no qual se soma às vozes de outr@s educador@s e estudantes. Pois é na formação de professores que me sinto completa, pois a minha voz ecoa e proporciona a beleza do pronunciamento de diversas outras vozes. Digo isto, pois tive/tenho a oportunidade de trabalhar como docente no Ensino Superior em universidades públicas. Minha primeira experiência aconteceu assim que saí da graduação, ao ingressar como tutora no curso de Pedagogia Semipresencial promovido pela UERJ, na disciplina Seminário V: Memória, História e Formação de Professores, sob coordenação do Professor Dr. Dirceu Castilho Pacheco, no qual eu trabalho até hoje. Além disso, trabalhei como professora substituta nos cursos de Pedagogia na UERJ-Maracanã e na UFFAngra dos Reis. Essas três experiências me deram a plena certeza de que eu quero continuar ecoando a minha voz, juntamente com tantas outras vozes na formação de professores.

Atualmente estou no Programa de Pós-graduação em Geografia da UERJ, campus Maracanã, cursando o doutorado, sob orientação da Professora Doutora Mônica Sampaio Machado. Confesso que o universo da vida acadêmica parecia muito distante para mim, uma vez 
que sou oriunda das classes populares e minha família majoritariamente possui formação de nível médio. Porém, ao realizar essa breve reflexão, percebo que foram vários os fatores que me motivaram a seguir os estudos no campo acadêmico: o desejo de aprender constantemente; o incentivo de parentes e amigos; as oportunidades e influências que tive; alguns docentes que conheci, pois acreditam e lutam por uma educação pública e de qualidade para todos, sobretudo como um meio de diminuir as desigualdades sociais, econômicas e culturais. Muitos desses professores e professoras eu conheci enquanto estive na formação inicial, isto é, na graduação, e que hoje são espelhos para mim e colegas de luta. Como diz um provérbio africano: "é sabendo de onde se vem que se pode saber para onde se vai”.

\section{Referências Bibliográficas:}

ALARCÃO, Isabel. Professores reflexivos em uma escola reflexiva. São Paulo: Cortez. Coleção questões de nossa época, 2010.

ALVES, Nilda; OLIVEIRA, Inês Barbosa (Orgs.). Pesquisa no/do cotidiano das escolas. Rio de Janeiro: DP\&A, 2001.

BARROS, Armando Martins de. Breves notas ao ensino de História da Educação. RJ: E-papers, 2004.

CAVALCANTI, Lana de Souza. Geografia da cidade: a produção do espaço urbano de Goiânia. Goiânia: Editora Alternativa, 2001.

CAVALCANTI, Lana de Souza. A Geografia Escolar e a Cidade: Ensaios sobre o ensino de geografia para a vida urbana cotidiana. Coleção Magistério - Formação e trabalho pedagógico. Campinas: Papirus, 2008.

FREIRE, Paulo. A educação na cidade. Rio de Janeiro: Paz e Terra, 1991.

GOMES, Paulo Cesar da Costa. Espaços públicos: um modo de ser do espaço, um modo de ser no espaço. In: CASTRO, Iná Elias de; GOMES, Paulo Cesar da Costa; CORRÊA, Roberto Lobato. Olhares geográficos: modos de ver e viver o espaço. Rio de Janeiro: Bertrand Brasil, 2012.

LEFEBVRE, Henri. O direito à cidade. São Paulo: Morais, 1991.

LEFEBVRE, Henri. A revolução urbana. Belo Horizonte: Ed. Da UFMG, 2002.

LE GOFF, Jacques. História e memória. Campinas: Ed. Da Unicamp, 1990.

MOTTA, Lia. As cidades: sua valorização e proteção como documentos. In: Cadernos de ensaios Memória e Educação. Rio de Janeiro: IPHAN, Paço Imperial, 2008.

PEREZ, Carmen Lúcia Vidal; ARAÚJO, Mairce da Silva; TAVARES, Maria Tereza Goudard. Cadernod@Professor@Alfabetizador@: Oficinas de alfabetização patrimonial e formação de professores. Rio de Janeiro: H. P. Comunicação, 2006.

PEREZ, Carmen Lúcia Vidal; ARAÚJO, Mairce da Silva; TAVARES, Maria Tereza Goudard (Orgs.). Memórias e Patrimônios: experiências em formação de professores. Rio de Janeiro: EdUERJ, 2009.

PESAVENTO, S. J. A cidade maldita. In: SOUZA, C. F.; PESAVENTO, S. J. (Orgs.) Imagens urbanas: os diversos olhares na formação do imaginário urbano. Porto Alegre: Editora da Universidade UFRGS, 1997. 


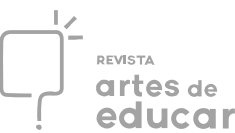

SANTOS, Boaventura de Sousa. Um discurso sobre as ciências. São Paulo: Cortez, 2010.

Revista Interinstitucional Artes de Educar. Rio de Janeiro, V. 2 N. Especial - pag 266-279 (jun - out 2016): "Vozes da Educação" 